\title{
Iothalamic Acid
}

National Cancer Institute

\section{Source}

National Cancer Institute. Iothalamic Acid. NCI Thesaurus. Code C61792.

An ionic tri-iodinated benzoate used as a contrast agent in diagnostic imaging. Like other organic iodine compounds, iothalamic acid blocks x-ray and appears opaque on x-ray film, thereby enhancing the visibility of structure and org ans during angiography, arteriography, arthrog raphy, cholang iography, and computed tomography (CT) scanning procedures. 